\title{
INTENSIVE TREATMENT OF GONORRHEA
}

Hodes, Gimbel and Burnett (I939) Journ. Amer. Med. Assoc., 113,

Janney Smith (I939) Journ. Amer. Med. Assoc., 113, I85I.

I6I4.

Kilgour (I939) C. M. A.J., 41, 445.

Kohlstaedt and PAGe (I940) Ann. Int. Med., 14, I29.

LoNg et al. (I940) Journ. Amer. Med. Assoc., 115, 364 .

LONG and BLISS (I939) " The Clinical and Experimental Use of Sulphanilamide and Sulphapyridine and Allied Com pounds."-Special addendum.

Long and Wood (I939) Ann. Int. Med., 13, 487.

McCANn (I938) Lancet, 2, Ioo.

MaCleod (1939) Journ. Amer. Med. Assoc., 113, I405.

NISSEN and ROESGAARD (I939) Ibid., 113, I924.

O'Meara (1940) Journ. Roy. Naval Med. Serv., 26, 3, 284.

PEPPER and Hoorack (I940) Am. J. Med. Sci., 199, 674.

Petro (I940) Journ. Roy. Naval Med. Serv., 26, 336.

Plummer and Emsworth (1939) Journ. Amer. Med. Assoc., 113, i847.

Plummer and McLellan (I940) ibid., 114, 943.

RAKE (I940) J. Bact., 39, 45.

RAvid and Chesner (I940) Am. J. Med. Sci., 199, 380.

ROBERTSON (1938) Lancet, $2,728$.

ROMCKE and VOIGT (I939) ibid., 2, 778.

SADUSK et al. (I940) Journ. Amer. Med. Assoc., 115, 1968.

Smith, Evelyn and Nolan (I940) C. M. A. J., 42, 27.

SNapper, Liu, Chung, Yu and Sun (I939) Chinese Med. J., 56, I.

Southworth and Cooke (I939) Journ. Amer. Med. Assoc., 112, I820. STEWART, RouRKe and Allen (I938) ibid., 110, I885.

TOOMEY (I939) ibid., 113, 3, 250.

TSAO et al. (1939) ibid., 113, r3I6.

UllaNd (I939) Nord. Medic., 4, 52.

\section{III}

\section{INTENSIVE TREATMENT OF GONORRHOEA AND NON-SPECIFIC URETHRITIS WITH SULPHAPYRIDINE}

\section{DISCUSSION}

Discussion of the PAPER READ Before The M.S.S.V.D. on 28.3.4I by Lieut.-Colonel A. J. King and Major D. I. Williams

Major T. E. Anderson said he had used the "intensive" method of treatment for three years and questioned the statement that it was unsuitable for out-patient treatment. Dr. Bowie and he had employed it routinely for a year and a half before the war in outpatient treatment, and Dr. Bowie was still using it without trouble.

Since the beginning of the war he had treated $\mathrm{I}, 800$ cases of gonorrhœa by this method and had been struck by the contrast in tolerance between in-patients (as military circumstances compel service cases 


\section{BRITISH JOURNAL OF VENEREAL DISEASES}

to be) and out-patients : side effects were unpleasant among outpatients, but less so than in in-patients, and vomiting was marked in half the percentage found among in-patients. He agreed with the importance of forcing fluids in in-patient treatment by the "intensive" method, but suggested that a psychological factor (more time for brooding and fewer interests) was an adverse one in hospitalised cases.

MAJOR R. M. B. MAcKenNA compared briefly the experiences which he had had in a somewhat larger number of cases of acute gonorrhoea in the male treated by means of a short intensive course of sulphapyridine.

His interest was largely from the clinical standpoint and had begun as a result of his dissatisfaction with an eight-day course of M. \& B. 693 . $\mathrm{He}$ and Major Wordingham had agreed that the best course of treatment was that whereby the patient received the maximum amount of the drug within the first 24 hours which he could safely tolerate, and that treatment should be continued for a second day to preserve the optimum blood concentration of the sulphapyridine. By trial and error, controlled to some degree by blood estimations, they had devised a course of 22 grammes of sulphapyridine in 48 hours. Tablets were crushed and given in milk every 4 hours by day and night, the doses given being $5,4,3$ and 2 grammes and thereafter I grm. up to a total of 22 grammes. He had been very satisfied with the results, as although cases of hæmaturia and temporary anuria had been met, these complications were rare and in his experience had always responded to treatment on the lines Lieut.-Colonel King had mentioned. He believed that the formation of the acetyl compound of sulphapyridine was probably idiosyncratic. In his experience the more severe complications of sulphapyridine therapy were usually preceded by a course of constipation. The advantages of a short intensive course of treatment were that they necessitated a minimal stay in hospital, and the likelihood of prostatitis or other complications developing was reduced to a minimum. He emphasised that his experience of this method of treatment had been confined to a selected section of the population, and that whilst he believed that for the healthy young adult male suffering from gonorrhæa, an intensive course of sulphapyridine was an excellent method of treatment, this method of treatment might not be applicable, without modification, to the population at large.

MAJOR R. T. WorDInGHAM said: Major MacKenna and I treated some 3,000 cases and the results have been most gratifying. There have been toxic complications but only of a minor degree, and considering the very excellent results obtained we consider them of little importance and certainly no contra-indication to the continuation of intensive therapy.

I shall outline the method I evolved after carefully controlled clinical experiments with varied dosage supported by bacteriological and biochemical examinations. The level of sulphapyridine in the blood was determined by Werner's method until two days after completion of the course. After critical examination of experimental cases it became obvious that the object was to obtain an effective level of sulphapyridine in the blood-in my experience at least 8-I2 mgm. per roo c.c.- - and maintain it for 36 to 48 hours. The drug is rapidly absorbed into the blood-stream and equally rapidly eliminated from the body, and it was found possible to reach a high concentration in 


\section{INTENSIVE TREATMENT OF GONORRHCA}

I 2 hours and maintain it for 36 hours. The drug is almost completely eliminated from the blood-stream in a further 24 hours.

In gonorrhœa we have typically a suppurative process of a mucous surface extending at a very early stage into sub-epithelial tissues and glandular structures.

Sulphapyridine by a process of simple diffusion passes quickly into sub-epithelial, glandular tissues, and their secretions. The object, therefore, is to "saturate" these tissues and yet avoid toxic manifestations.

I shall confine my remarks to a description of my " Two-day Course" -22 grammes of M. \& B. 693 in 48 hours-as the other modification merely consists in giving the initial six doses in 24 hours.

I. The tablets are crushed and are given in milk, and their administration is spaced 4 -hourly throughout the whole 24 hours. This is necessary to maintain the effective concentration, which has resulted from the heavier initial dosage.

The coincident administration of potassium citrate, or sodium citrate, or potassium bicarbonate in 30 grain doses 2-hourly has been practised. This is a factor of some importance in avoiding hæmaturia.

The initial dosage was 5 grammes (Io tablets) followed by diminishing doses of 4 grammes, 3 grammes, 2 grammes, I gramme and then I gramme 4 hourly up to a total of 22 grammes in 48 hours.

II. Rest in bed-complete mental and physical relaxation.

III. Attention to bowels and a low-residue diet equivalent to three pints of milk daily. Also an average of ten to twelve pints of water during the day, and no smoking was permitted.

IV. Attention to local cleanliness and irrigation with potassium permanganate $I$ : ro,ooo twice daily.

Free drainage is most important, and is aided by administration of large amounts of fluids and the exhibition of the alkalis.

Major MacKenna and myself are both agreed that following this technique toxic and unpleasant manifestations, with the possible exception of hæmaturia and vomiting, are negligible.

Vomiting, after much observation and careful examination of gastric analysis and vomitus, we regard as central in origin and greatly affected by psychological factors and smoking. The removal of a patient affected in this way to a side ward has immediately resulted in its cessation in others. Vomiting at first sight appears distressing but it is unnecessary to discontinue the drug.

Hæmaturia is in another category, and is not related to actual dosage. I have seen it in cases of small dosage, due to personal idiosyncrasy. It is an irritative phenomenon due to the crystals of the acetylated derivative of sulphapyridine. Of our cases an average of I in 300 patients has suffered with hæmaturia-often only transientand examination of the kidney function at the end of the three months' surveillance has shown no permanent damage. I am convinced that our experiences of this complication have been more fortunate due to pushing fluids and alkalis.

After completion of the course, local treatment and fluids are continued and ordinary diet and duties in wards and fatigues are resumed without incident. After two days an intra-urethral smear and an all-night specimen of urine are examined.

In the presence of a crystal-clear urine, absence of pus cells in the 


\section{BRITISH JOURNAL OF VENEREAL DISEASES}

smear, and no abnormality in the prostatic secretion, the initial tests for apparent cure are instituted. Alcohol is given and a provocative injection of vaccine equal to 300 million gonococci.

The case attends on the two succeeding mornings, and if the results are satisfactory, a urethroscopy is done and he is discharged to surveillance. At the end of three months more than 90 per cent. of such cases have been pronounced " cured " after the most rigid teststhe average stay in hospital being eleven days.

By a judicious combination of local measures and intensive therapy the results have been equally good in the more complicated cases. In the few resistant cases the institution of a course of sterile milk injections, followed by a further course of intensive therapy, has proved its efficacy.

Major Prebble said: I have had very little experience with the intensive method. My usual course consists of eight tablets daily for 2 days, followed by six tablets daily up to a total of not more than ten days and the results obtained have been most satisfactory. I have experienced very little trouble with sulphapyridine and it has seldom been necessary to stop before completion of a course of treatment. A preliminary purgative is most useful and as a routine all my patients are given calomel gr. ii before commencing chemotherapy; also copious fluids are essential. I have only had one serious complication in some two thousand cases and that unfortunately with fatal results. The patient, a recently infected case, was given $28 \mathrm{gms}$. of sulphapyridine over ten days. At the end of this time a slight purulent discharge with no gonococci was present and irrigations of $\mathrm{KMnO}_{4}$ were given. At the end of a week a further $28 \mathrm{gms}$. of sulphapyridine were given over ten days. Two days later he complained of dysphagia and gargles were ordered for tonsillitis. Next day he had a temperature of ro4.6 and still severe dysphagia. A blood count showed 2,400 white cells but no neutrophils and sodium pentonucleotide was given together with Hepatex. The following day he developed œdema of the glottis and a tracheotomy was performed. His white count rose to 5,600 but he died suddenly the next day. I consider it essential that a cell count should be done before a second course of the drug is given.

I have treated a number of early acute cases with sulphathiazole using various schemes of dosage. I have not tried the " one-dose cure" as yet, but I did try a series of cases with 18 tablets in 24 hours. In all cases gonococci were absent 24 hours after completion of treatment but pus cells were still present. Smears were taken daily and without any further treatment the number of leucocytes decreased each day. At the end of seven days a number of cases were completely dry. The drug appears to be virtually non-toxic but it was not so effective as sulphapyridine.

MAJOR S. M. LAIRD said the results obtained in acute uncomplicated gonococcal urethritis in the male, using $24 \mathrm{gm}$. sulphapyridine spread over 4 days, combined with a high fluid intake and urethral irrigation, are so uniformly satisfactory that more intensive dosage appears not only unnecessary, but also undesirable. With the former course of treatment clinical cure is achieved in four or five days and the patient can be discharged from hospital on the seventh day.

As a general rule, in civil practice, straight-forward cases of gonorrhœe responded better to out-patient, as opposed to in-patient, treat- 


\section{INTENSIVE TREATMENT OF GONORRHEA}

ment and this experience supports Major Anderson's contention that hospitalisation of such cases provides an unsatisfactory psychological background for the patient's treatment.

Renal irritation due to sulphapyridine can be conveniently described in three stages. In the first, the hæmaturia is only detected by microscopic examination and may be associated with discomfort in the lumbar region; in the second, hæmaturia is obvious on naked-eye examination and the pain is severe and usually resembles typical renal colic ; and, in the third and most serious stage, there is pain, hæmaturia and oliguria which, unless successfully treated, may progress to anuria, nitrogen retention and death. The kidneys, in such cases, are frequently palpable and tender and the hydronephrosis noted at open operation and autopsy explains such clinical findings. The right kidney appears to be affected more frequently and more severely than the left.

Five cases of hæmaturia have been met with; the incidence, and the part played by the fluid intake, are well illustrated by the following figures :-

\begin{tabular}{|c|c|c|c|}
\hline Number of Cases. & $\begin{array}{l}\text { Daily Dosage of } \\
\text { M. \& B. } 693 \text {. }\end{array}$ & Fluid Intake per Diem. & $\begin{array}{c}\text { Number of Cases of } \\
\text { Hæmaturia. }\end{array}$ \\
\hline $\begin{array}{r}\text { I62 } \\
323 \\
\text { I04 } \\
\text { I40 } \\
65\end{array}$ & $\begin{array}{l}3 \mathrm{gm} . \\
4 \mathrm{gm} . \\
4 \mathrm{gm} . \\
6 \mathrm{gm} . \\
6 \mathrm{gm} .\end{array}$ & $\begin{array}{r}\text { Over } 3,000 \text { c.c. } \\
\text { Over } 3,000 \text { c.c. } \\
2,000 \text { c.c. } \\
2,000 \text { c.c. } \\
\text { Over } 3,000 \text { c.c. }\end{array}$ & $\begin{array}{l}\text { Nil. } \\
\text { Nil. } \\
\text { I case } \\
4 \text { cases } \\
\text { Nil }\end{array}$ \\
\hline
\end{tabular}

To reduce the risk of hæmaturia, the fluid intake must be in excess of 3,000 c.c. per day. When hæmaturia develops, the drug should be stopped forthwith and fluids forced. Urine output and the blood urea must be measured. Anuria of twelve hours' duration is a signal for ureteric catheterisation which proved dramatically successful in relieving the complete renal obstruction which supervened in one of the five cases of hæmaturia.

MAjor Douglas J. CAmpbell said he did not use intensive therapy but used a moderate dosage of 4 grams a day for 5 to 7 days.

From impressions derived from questioning patients treated intensively and from notes forwarded by other hospitals he felt that such drastic measures were uncalled for both psychologically and medically.

Under his treatment even moderate upset was unusual, patients could perform light duties, moderation of diet was unnecessary and the number of days in hospital was actually better than those quoted under intensive therapy.

He had met only two cases of hæmaturia. In one blood appeared after an initial dose (I gram) and, after 24 hours off treatment, reappeared when two further tablets were taken. The other case had had eight infections of gonorrhœa. The right kidney was obviously surgical and the condition flared up with obstructive symptoms and hæmaturia under M. \& B. 693.

Complications such as prostatitis seemed prevalent in cases treated 


\section{BRITISH JOURNAL OF VENEREAL DISEASES}

with intensive therapy, whether due to the short continuity of treatment or the growing tendency to too early instrumentation and prostatic massage.

Taken all round, with the discomfort to the patient, the very obvious dangers of treatment, and the difficulties of diet and nursing with an already short and hard-worked staff, he did not consider intensive therapy the treatment to be advised.

MAJOR D. I. WiLliamS said: " A number of points have been raised which may further our knowledge. The psychological effect on the other patients of one man vomiting is an undoubted factor in the high incidence thereof. The ban on smoking would seem to be a good suggestion. It is not possible to agree that the Intensive Method is a nerve-shattering procedure. The only sources of anxiety were the cases of anuria and the proportion of these was small. Despite Major Anderson's protestations, it is difficult to believe that it is justifiable to treat out-patients intensively.

"This paper may seem to have produced an impression unfavourable to the 'Intensive Method.' If this be so, I would say that I am strongly 'pro' the method, and I believe that in the light of present knowledge our results could be considerably bettered with a smaller proportion of toxic manifestations and with safeguards against, if not with complete avoidance, of the more serious effects of the drug."

LT.-COL. T. E. OsmoND said that he favoured the intensive treatment of soldiers on the grounds that (I) it meant a shorter time in hospital, (2) many patients preferred it, (3) it was less likely to cause agranulocytosis, (4) it was doubtful if it caused more hæmaturia, (5) it produced less sulphonamide resistant cases, and (6) it was accompanied by fewer complications.

He wished to stress the point that sulphapyridine should never be given continuously for more than seven days without an examination of the blood.

As regards vomiting, it had been shown that this was due to stimulation of the vomiting centre from various sites and not only from the gastro-intestinal canal and that therefore substances like sodium bicarbonate would frequently fail to control it.

It had been stated that hæmaturia was due to the deposit of crystals of acetylated sulphapyridine in the tubules of the kidney in a hyperacid state : this seemed to be confirmed by the specimens shown by Major Whitehead.

There were four causes of anuria: (I) blocking of both ureters, (2) a fall of blood pressure below 70-90 mm. of $\mathrm{Hg}$., (3) chronic renal disease and (4) reflex or surgical anuria : he thought the possibility of the last should be kept in mind.

As regards treatment, this should consist of first glucose and saline, secondly catheterisation of the ureters, and if this did not succeed there should at once be carried out a pyelostomy or nephrostomy.

MAJOR W. V. FAWKNER-CORBETT said he had been greatly interested by the uniformity, though there were points of difference, regarding the drug-taking. It was interesting to hear speakers substantiating. the need for a great intake of fluid; the addition of alkali and the amount of the drug to be taken.

He had been impressed by the fact that ambulatory gonococcal patients could take so much in the way of a drug and yet carry out 


\section{INTENSIVE TREATMENT OF GONORRHEA}

their daily work quite efficiently. According to his records, the results were singularly encouraging and singularly uniform. $\mathrm{He}$ agreed entirely with Colonel Osmond's remarks in regard to the drug-taking not being extended beyond seven days at a time.

From the strictly administrative side he wanted to emphasise that it was for the clinical side to endeavour to help the administrative side in that the longer the men were in bed the more flabby they got. The patients had on recovery to return and become efficient soldiers. At present a patient finishing in hospital went back to his unit but he was not an AI man.

MAJOR A. G. FERGUSSON said : "Although for the past six months I have been engaged in work of a purely dermatological nature, I had some experience in civilian life of the 'I4-day treatment' of gonorrhœa with sulphapyridine. At the beginning of the war, however, I became associated with Major Anderson, and rapidly became a convert to the so-called 'intensive' method, which seemed to surpass in immediate and also apparently in follow-up results anything achieved by means of the 'I4-day' therapy.

"As regards treatment, preventive and curative, of the vomiting so often met with during the 'intensive' course, I should like to agree that tablets are best tolerated if administered finely ground and in milk or water. I was extremely interested to hear Col. Osmond's remark that the vomiting during treatment was not due to local action on the stomach mucosa, but might be of reflex nature.

"We administered Potassium Bromide in dosage of 30 to 60 grs. twice or thrice daily with beneficial results in severe gastric upset. It seemed to us that the action of the sedative might well be an inhibitory one on a reflex path with cerebellar connections."

DR. R. Forgan said that, valuable as sulphapyridine had undoubtedly been in the treatment of gonorrhœea, it might well be that other sulphonamide compounds would in the near future prove to be as effective and less likely to cause gastric or renal intolerance.

We spoke of the intensive chemotherapy of gonorrhœa, but it should be remembered that an equal or even heavier daily dosage was employed in other acute infections. Contrasting the incidence of hæmaturia, renal colic, oliguria and anuria in afebrile gonococcal conditions with the occurrence of these symptoms in meningococcal and pneumococcal disease, it was remarkable that in gonorrhœa their onset was apparently earlier in the course of treatment. The first signs of renal discomfort may occur about eighteen hours after commencing sulphapyridine. In febrile conditions as a rule it was forty-eight hours or longer. It seemed possible that while the temperature was elevated there might be less tendency (provided that plentiful fluids were given) for crystallisation to occur in the urinary tract ; for, of course, the solubility of the drug increased with temperature. It was a practice to give an intravenous injection of T.A.B. vaccine if at the end of the three days' course of chemotherapy the response had not been entirely satisfactory. To minimise the possibility of urolithiasis it might be worth while to raise the temperature by protein shock on the very first day of drug treatment; and the elevated temperature might also enhance the therapeutic action of the drug.

Where kidney dysfunction had actually developed and ureteric v.D. 


\section{BRITISH JOURNAL OF VENEREAL DISEASES}

lavage was being carried out, the irrigating solution should be warm to hasten solution of the deposited acetyl sulphapyridine.

Whatever its virtue might be in the treatment of gonorrhœa the administration of alkalis as a measure designed to prevent deposition of crystals was probably of no value, for the solubility of conjugated sulphapyridine was little affected by any change that could be brought about in the $p \mathrm{H}$ of the urine. Far the most important safeguard against renal upset was the forcing of fluids, a measure that ensured higher dilution in the urine without diminishing the concentration of the drug in the blood-stream. It had been shown that afternoon that only in those cases where fluid intake had been restricted had serious symptoms of renal intolerance occurred.

Col. L. W. HARrison said that he wondered if much of the drug given in such an intensive treatment as that originally recommended by Bowie et al. was not wasted, the first dose of 4 grammes having effected the cure. Gaté and Guilleret (J. Med. Lyon, I940, 21, I87) claimed to have cured ro6 out of Io9 cases of acute gonorrhœa in the male with a dose of 9 grammes of sulphamethylthiazole (68 cases) or of sulphathiazole (4I cases) which they preferred administered in 24 hours. The spacing of the dosage which they recommended was something like this : starting at 3 p.m., the patient took two tablets every two hours until II p.m., and resuming the following day at 6 a.m., took two then and two every three hours until 3 p.m. But much more impressive than this was the investigation of Prof. G. Miescher (Schweiz. med. Wschr., I940, 270, 89I) because by systematic steps he progressed from a 6-day treatment in which he used as adjuvants of sulphathiazole, vaccines and local treatment, to a onedose administration of sulphathiazole without any adjuvant treatment at all ; in fact a true " therapia sterilisans magna."

With his 6-day sulphathiazole-vaccine-local-treatment cure he achieved $I 8 I$ cures in $I 87$ cases ; with a six-day treatment without any adjuvant vaccine or local treatment his cures were 80 in 82 cases, so he proceeded to a two-day treatment, giving two tablets five times each day, and here claimed 28 cures in as many cases.

In his one-day treatment he tried nine different systems of multiple dosage before arriving at the one dose. In the cases treated for one day on multiple dosage plans he claimed 73 cures in 75 cases. Fourteen cases were treated with a single dose, 3 with ro tablets, 6 with 6 tablets and 5 with 4 tablets, and in this series there was one failure. Perhaps an important contributory factor in these astonishing results was the method of administration of the drug ; it was given powdered up with sugar between meals, being washed down with half a litre of limeblossom tea. This may be important in view of recent work which seems to indicate a strong inhibitory effect of stomach acids on absorption. Miescher's tests showed that the blood concentration of the free drug after administration of 5 grammes of sulphathiazole was Io mgm. per roo c.c. from 2 to 4 hours later, over $6 \mathrm{mgm}$. at 6 hours, and $4 \mathrm{mgm}$. at 8 hours. In the urine, the peak concentration of unacetylated drug was 4 per $\mathrm{I}, 000$ at 6 hours. Knowing what we do of the requirements in this respect for destruction of micro-organisms and of the relatively short life of the individual gonococcus, $1 \mathrm{t}$ is perhaps not very surprising that it has been found possible to cure gonorrhœa with one dose. At any rate it will be agreed that this method of treatment is well worth 


\title{
LABORATORY FACILITIES IN THE DIAGNOSIS
}

further investigation. Another worker who has had some success with a one-day treatment is E. Ramel (Rev. Suisse romand., I940, Nos. 7 and 8). He treated I5 cases by giving them a tablet every hour for five doses and a sixth tablet was given 3 hours later. This treatment was supplemented by the induction of an attack of fever by means of an injection of Pyrifer. Miescher doubts if the Pyrifer was necessary.

\section{IV \\ THE NECESSITY OF THE CLINICIAN MAKING THE BEST USE OF LABORA- TORY FACILITIES IN THE DIAGNOSIS OF VENEREAL DISEASES *}

\author{
By Dr. I. N. ORPWOOD-PRICE
}

WHEN I was first asked to deliver a lecture on this subject, I felt a little diffident about talking, even for a short while, on what must appear to be so well-known to most people treating V.D. Further reflection, however, persuaded me that many clinicians do not know how to make the best use of a V.D. Laboratory. The reasons for this appear to be manifold but the chief one seems to be that the majority of practitioners have not served any apprenticeship, even of short duration, in a laboratory and many have little more than a nodding acquaintance with its work. Many years ago Colonel Harrison endeavoured to persuade the budding V.D. specialist to spend some time in the laboratory before undertaking the clinical side of this work. Unfortunately, this excellent advice was rarely followed and many deprived themselves of knowledge, the lack of which even they must occasionally regret. This lack of knowledge has been demonstrated clearly during the last few years if one reads some of the vast number of papers published about the value of the sulphonamide group of drugs. The clinical details are usually well-documented but the support or otherwise of laboratory evidence is often lacking, or is so primitive as to be valueless.

Now, as I see it, there are four main functions of a

* Based on an address delivered to the Medical Society for the Study of Venereal Diseases on June 24th, 194 I. 